\title{
Synthesis and Properties of Energetics Metal Borides for Hybrid Solid-Propellant Rocket Engines
}

\author{
S.S. Bondarchuk, A.E. Matveev, V.V. Promakhov, A.B. Vorozhtsov, \\ A.S. Zhukov, I.A. Zhukov and M.H. Ziatdinov
}

\begin{abstract}
In this paper, the problems of production and characterization of microsized metal borides (including aluminum, titanium, magnesium) are discussed. The preferences of application for high-energy materials are presented. The problems of chemical stability and chemical compatibility are discussed. A technique for production of metal borides is also described which is known as self-propagating high-temperature synthesis (SHS) and the subsequent mechanical treatment. The result is microsized borides which have an average size of around 5 microns with a sharp curve for distribution sizes. The purity is enough for use as fuel of high-energy materials hybrid solid-propellant rocket engines. The results of SEM, X-Ray, DSC, and TG analyses are also presented and discussed.
\end{abstract}

S.S. Bondarchuk $(\bowtie) \cdot$ A.B. Vorozhtsov · A.S. Zhukov

Doctor of Physico-Mathematical Sciences, Tomsk State University, Tomsk, Russia

e-mail: isbi@mail.ru

A.B. Vorozhtsov

e-mail: abv1953@mail.ru

A.S. Zhukov

e-mail: Zhuk_77@mail.ru

A.E. Matveev

Tomsk State University, Tomsk, Russia

e-mail: cool.mr.c@mail.ru

V.V. Promakhov · I.A. Zhukov · M.H. Ziatdinov

Candidate of Engineering Sciences, Tomsk State University, Tomsk, Russia

e-mail: vvpromakhov@mail.ru

I.A. Zhukov

e-mail: gofra930@mail.ru

M.H. Ziatdinov

e-mail: ziatdinovm@mail.ru

S.S. Bondarchuk

Tomsk State Pedagogical University, Tomsk, Russia

(C) The Author(s) 2018

K.V. Anisimov et al. (eds.), Proceedings of the Scientific-Practical Conference

“Research and Development - 2016”, https://doi.org/10.1007/978-3-319-62870-7_54 
Keywords Metal borides • High-energy materials - SHS process $\mathrm{X}$-ray analysis $\cdot$ Properties $\cdot$ Oxidation

Safety requirements and the cost of placement into the required orbit determine the trends of improvement of propulsion systems of boosters. A possible compromise is associated with the use of hybrid engines including solid-propellant rocket engines (HSRE) which can also use liquid and gaseous oxidizers [1, 4]. Borides are advanced materials for use as fuel additives for energetic systems. The potential of use of metal powders ( $\mathrm{Al}, \mathrm{Mg}$ and others) is almost exhausted today. New additives with higher energy characteristics are required. Boron is the best alternative so far. Heat of combustion for boron is almost two times higher than for aluminum. Production technologies for boron and its compounds are well known and tested. Moreover, boron is nontoxic, occurs in nature in large quantities, and is produced on an industrial scale.

From the very beginning of the research in the field of combustion synthesis, a lot of promising systems from the practical point of view were determined, however, a self-sustaining process was not possible due to their insufficient exothermicity. The first approach was pumping of additional heat by means of preheating of initial mix in a resistance furnace. It was the production of intermetallides when the operation of increasing of initial temperature of reaction mix was used for the first time for SHS reactions. The increase of initial temperature of the mix up to 50$500{ }^{\circ} \mathrm{C}$ made it possible to synthesize aluminides of $\mathrm{Ni}, \mathrm{Co}, \mathrm{Ti}, \mathrm{Cr}, \mathrm{Mo}$, and other metals in combustion mode. When such furnace SHS technology is used in practice, its characteristic advantages such as zero energy consumption, simplicity of equipment and low time consumption are reduced to zero.

The use of potentially high boron exothermicity becomes possible if it is used in the form of metal borides which also have high values of the heat of combustion. It was found that borides of $\mathrm{Al}$ and $\mathrm{Mg}$ as well as $\mathrm{Ti}$ and $\mathrm{Zr}$ are the most promising ones.

This paper describes a laboratory technology of production of borides of $\mathrm{Al}, \mathrm{Ti}$, $\mathrm{Mg}$, etc., including double and mixed compounds. Elemental boron, boron carbide, and iron boride were used as boron source. The experimental results of XRD analysis, TGA, and particle size analysis obtained for synthesized powders are given.

Self-propagating high-temperature synthesis is the most suitable method for the development of new energy materials which makes it possible to produce ultrapure product with target chemical and phase composition by means of adjustment of synthesis parameters. Preliminary studies have indicated that it is possible to produce borides with high content of target phase. According to DTA data, the degree of oxidation of obtained powders exceeds $95 \%$.

If we compare the heat release of different metals (Table 1), it appears clear that boron and lithium have the best characteristics for this purpose.

Lithium cannot be used due to its toxicity and low processability (low melting point and high chemical activity). Moreover, metallic lithium is rare and very expensive. Therefore, there are no alternatives are to boron regarding exothermicity and availability. The heat of combustion for boron is almost two times higher than that for aluminum and boron has a high availability in nature. However, due to specific properties of its oxide $\mathrm{B}_{2} \mathrm{O}_{3}$ (high boiling point and high viscosity of oxide 
Table 1 Heat of combustion of energetic metals [2]

\begin{tabular}{l|l}
\hline Element & Heat of combustion, $\mathrm{kJ} / \mathrm{g}$ \\
\hline $\mathrm{Li}$ & 43.5 \\
$\mathrm{~B}$ & 57.2 \\
\hline $\mathrm{Mg}$ & 25.1 \\
\hline $\mathrm{Al}$ & 31.4 \\
\hline $\mathrm{Si}$ & 32.2 \\
$\mathrm{Ti}$ & 15.7 \\
\hline $\mathrm{Zr}$ & 12.0 \\
\hline
\end{tabular}

melt), the rate of oxidation of elemental boron in fuel composition is unacceptably low. Also, boron oxide causes an appreciable agglomeration which is an extremely undesirable phenomenon. Well-known fundamental works by A. Gany and other scientists demonstrate the possibilities of using boron as fuel, however, there are no widespread technologies making it possible to use this element as a component of high-energy materials [3].

Currently, the optimal solution for the task of improving the efficiency of metallic additives to fuel compositions would be a full or partial transition to the use of metal borides.

This paper provides an overview of the results following a comprehensive analysis of the properties of different micro- and nanoparticles which can be used as additives for HEM.

The use of potentially high boron exothermicity becomes possible if it is used in the form of metal borides which also have high values of the heat of combustion. The oxidation of boron particles unfortunately results in the formation of a solid layer of oxide $\mathrm{B}_{2} \mathrm{O}_{3}$ and the diffusion of oxygen through this layer is hindered. The oxidation of metal borides does not result in the formation of an oxide layer impenetrable for oxygen. Diffusion of oxygen through the faulted layer of complex oxides is facilitated and the degree and rate of oxidation is increased.

It was found that borides of aluminum and magnesium as well as titanium and zirconium are the most promising (Table 2). Values of the heat of combustion for these borides are given below. Heat of combustion of borides is significantly higher than the values for corresponding metals.

Vacuum heat technology is used for boride synthesis. At the same time, the formation of borides is associated with significant heat liberation. This energy is

Table 2 Heat of combustion of energetic borides

\begin{tabular}{l|c}
\hline Borides & Heat of combustion, cal/g \\
\hline $\mathrm{AlB}_{2}$ & 9.430 \\
\hline $\mathrm{AlB}_{12}$ & 12.160 \\
\hline $\mathrm{MgB}$ & 9.050 \\
\hline $\mathrm{TiB}_{2}$ & 5.700 \\
\hline $\mathrm{Mg}_{0.5} \mathrm{Al}_{0.5} \mathrm{~B}_{2}$ & 9.240 \\
\hline $\mathrm{ZrB}_{2}$ & 4.230 \\
\hline
\end{tabular}


often enough for the process in combustion mode according to self-propagating high-temperature synthesis (SHS). Large-scale furnace equipment is not necessary in this case, and most importantly, the synthesized materials have better performance characteristics.

At the same time, there are a lot of systems including borides which do not have enough heat release for SHS processes. In such cases, there are two possible variants of the SHS process: Energy can be pumped in from external sources or energy can be recovered. External energy can be introduced in the form of physical or chemical heat. In case of physical heating, the initial SHS mix is placed into an electric furnace and heated up to the required temperature and then an SHS reaction is initiated. In this case, both layer-by-layer and overall combustion modes can be provided. Preheating of exothermic mix or its part is widely used in metallothermic production of metals and master alloys in particular.

Another possible option of improving the exothermicity of the mix is by introducing additional chemical heat. This method is widely used in aluminothermy in the process of production of complex ferroalloys.

A.G. Merzhanov [6] stated the five most typical situations in the process of classification of chemical routes of SHS reactions. One of these types of routes was called "chemically independent routes in thermally coupled systems ("chemical furnace")". In these cases, chemical reactions proceed independently, however, the heat from the more exothermic reaction provides energy for the less exothermic one.

From the very beginning of the research in the field of combustion synthesis, a lot of promising systems from the practical point of view were determined, however, a self-sustaining process was not possible due to their insufficient exothermicity. The first approach was pumping of additional heat by means of preheating the initial mix in a resistance furnace. It was the production of intermetallides when the operation of increasing of initial temperature of reaction mix was used for the first time for SHS reactions. The increase of the initial temperature of the mix up to $50-500{ }^{\circ} \mathrm{C}$ made it possible to synthesize aluminides of $\mathrm{Ni}, \mathrm{Co}, \mathrm{Ti}, \mathrm{Cr}, \mathrm{Mo}$, and other metals in combustion mode. When such furnace SHS technology is used in practice its characteristic advantages such as no energy consumption, simplicity of equipment, and low time consumption are reduced to zero.

The next step which extended the potential of $\mathrm{SH}$ synthesis for low-exothermicity systems was the invention of a so-called "chemical furnace". This term was coined by V.M. Maslov [5] for the process of synthesis of intermetallides in $\mathrm{Nb}-\mathrm{Al}$ and $\mathrm{Nb}-\mathrm{Ge}$ systems. Equiatomic mixture of $\mathrm{Ni}$ and $\mathrm{Al}$ powders with combustion temperature of $1640{ }^{\circ} \mathrm{C}$ was used as a material of "chemical furnace".

The principle of the "chemical furnace" could also be applied to the synthesis of compounds such as $\mathrm{WC}, \mathrm{NbC}, \mathrm{SiC}, \mathrm{B}_{4} \mathrm{C}, \mathrm{Al}_{4} \mathrm{C}_{3}, \mathrm{VC}, \mathrm{Mo}_{2} \mathrm{C}, \mathrm{WB}, \mathrm{WB}_{2}$, and others which do not have enough heat liberation for a general SHS process [7, 8]. In this case, mixtures with higher burning temperatures such as $\mathrm{Ti}$ or $\mathrm{Zr}$ powders with $\mathrm{C}$ or $\mathrm{B}$ (Table 3) can be used as materials for a "chemical furnace". 
Table 3 Heat of formation of energetic borides

\begin{tabular}{l|c}
\hline Borides & Heat of formation, cal/g \\
\hline $\mathrm{TiB}_{2}$ & 1006.6 \\
\hline $\mathrm{ZrB} 2$ & 778.3 \\
\hline $\mathrm{TiB}_{12}$ & - \\
\hline $\mathrm{ZrB}_{12}$ & 542.8 \\
\hline $\mathrm{AlB}_{2}$ & - \\
\hline $\mathrm{AlB}_{12}$ & - \\
\hline $\mathrm{MgB}_{2}$ & 289.4 \\
\hline $\mathrm{MgB}_{12}$ & 223.1 \\
\hline
\end{tabular}

In the case of insufficient heat liberation, the combustion synthesis can be combined with elements of the furnace synthesis. Energy is pre-pumped into the system providing a further combined SHS process. An initial mix of metal and boron is used for the implementation of boride combustion synthesis:

$$
\begin{aligned}
& \mathrm{Ti}+2 \mathrm{~B} \rightarrow \mathrm{TiB}_{2}, \\
& \mathrm{Al}+2 \mathrm{~B} \rightarrow \mathrm{AlB}_{2}, \\
& \mathrm{Zr}+2 \mathrm{~B} \rightarrow \mathrm{ZrB}_{2} .
\end{aligned}
$$

A laboratory-scale production technology for borides of $\mathrm{Al}, \mathrm{Ti}, \mathrm{Mg}$, and other metals including double and mixed compounds has been tested. This has resulted the synthesized powders having particle sizes of $\delta_{50} \approx 10 \mu \mathrm{m}$.

Production of borides using the SHS method involves three stages: preparation of the exothermic mix, combustion synthesis, and product processing. The first stage includes the operations of batching and mixing of initial powders in stoichiometric proportions and production of cylindrical samples with different diameters.

After this, the compressed tablets are placed inside a research SHS reactor with a sealed working chamber which is vacuumized and filled with an inert gas (Ar, He) to provide pressure level of 0.2 MPa. Ignition is then initiated by application of electrical pulse to a tungsten spiral with subsequent formation of a plane combustion front.

At the end of propagation of a synthesis wave and sample cool down, the SHS reactor is depressurized and the sample is processed and analyzed. Particle size distribution and phase composition of the powder produced by milling in a ball mill is determined along with the free boron content. Energy characteristics of the boride powder are then analyzed using a DTA (Differential Thermal Analysis) method.

The results of X-ray phase analysis of some synthesized borides are shown in Fig. 1 as an example. Particle size distribution as well as DTA (Fig. 2) data for $\mathrm{AlB}_{2}$ were obtained.

According to X-ray phase analysis data, the content of the target phases in the powders studied comprised: $88.04 \%$ for $\mathrm{Al}_{0.5} \mathrm{Mg}_{0.5} \mathrm{~B}_{2}$ phase, $93.18 \%$ for $\mathrm{AlB}_{2}$ and $98.43 \%$ for $\mathrm{TiB}_{2}$. The average size for target phases did not exceed $30-40 \mathrm{~nm}$. 

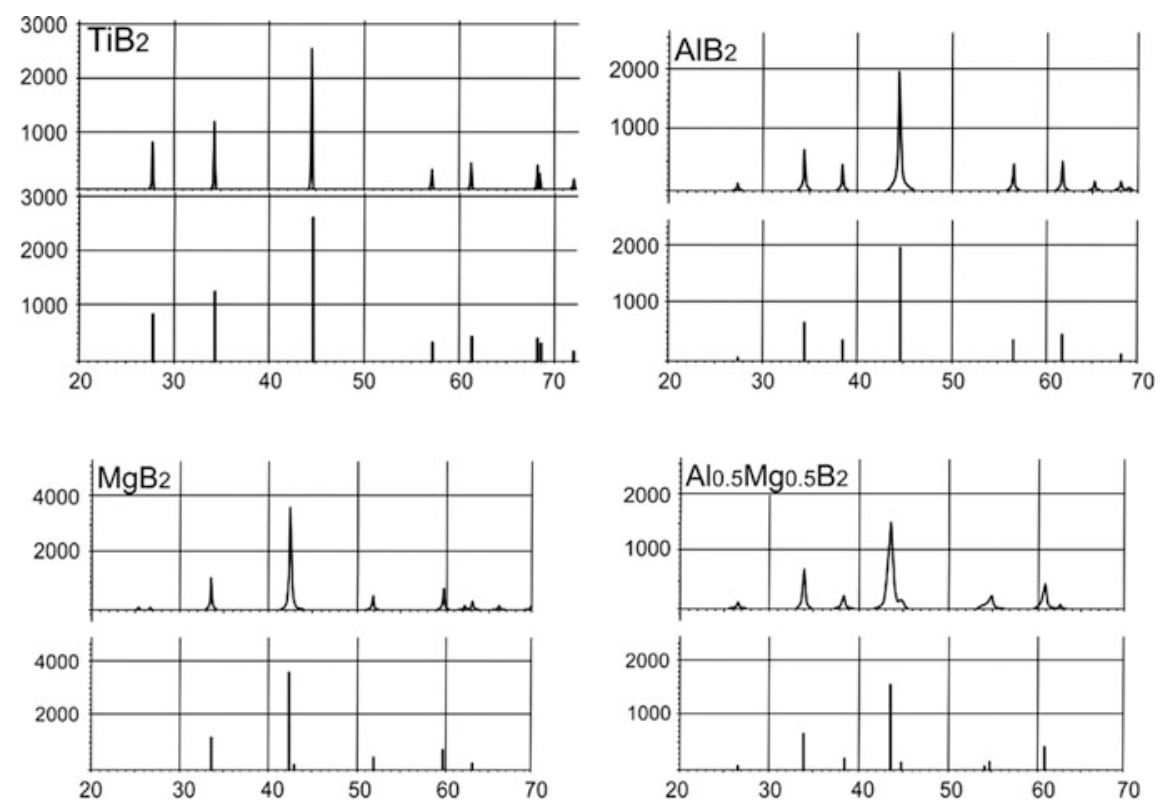

Fig. 1 Typical X-ray images of SHS of energetic borides
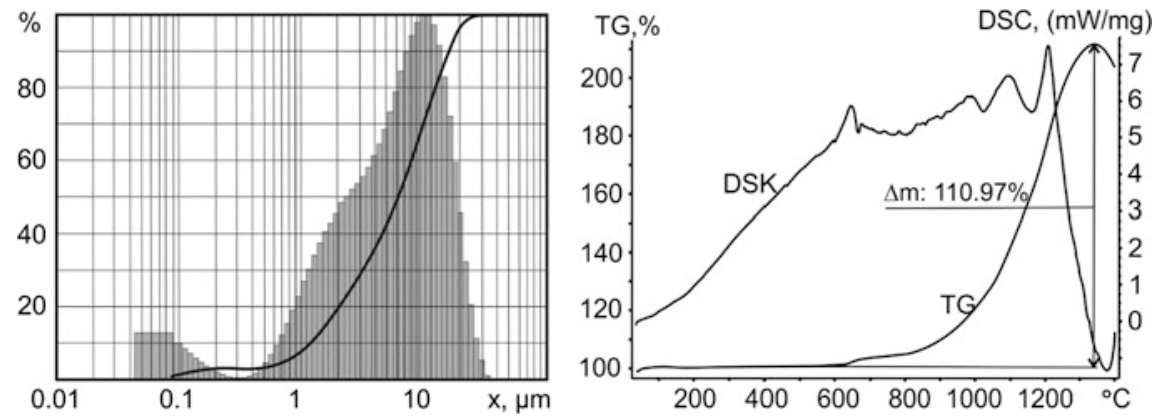

Fig. 2 Particle size distribution and DTA analysis data for $\mathrm{AlB}_{2}$ powder produced by means of SH synthesis

The analysis of the particle size distribution in $\mathrm{AlB}_{2}$ powders have indicated that the average particle size comprises $6.2 \mu \mathrm{m}$. The maximum size of the fraction was $\delta_{99}-24.9 \mu \mathrm{m}$. The structure of some powders $\left(\mathrm{AlB}_{2}, \mathrm{TiB}_{2}, \mathrm{AlB}_{12}\right)$ is shown in Fig. 3. According to DTA data, the sample mass increased $\sim 2.17$ times. The increase in the mass was thought to be due to the following reaction $2 \mathrm{AlB}_{2}+$ $3 \mathrm{O}_{2}=\mathrm{Al}_{2} \mathrm{O}_{3}+\mathrm{B}_{2} \mathrm{O}_{3}$. Comprises $\sim 2.26$ UNCLEAR. It was also demonstrated that the degree of oxidation was $96 \%$. General information on all received oxidation borides compared with aluminum and boron are shown in Fig. 4. 
(a)

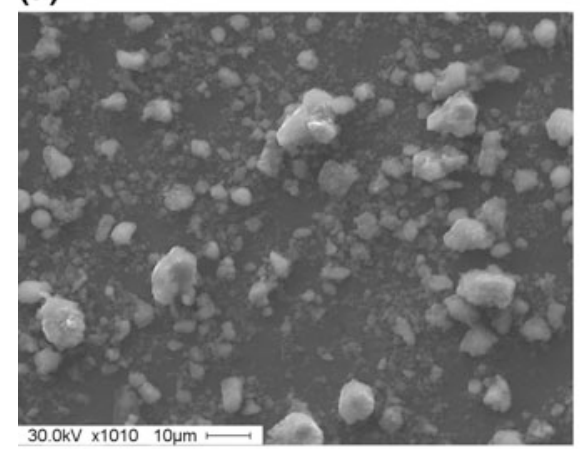

(b)

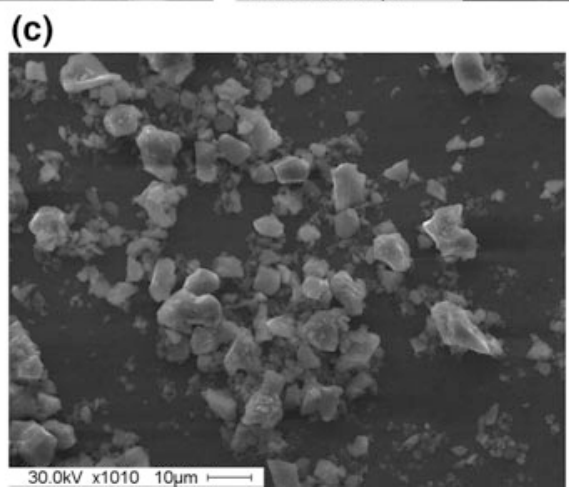

Fig. 3 Typical structure of energetic borides $\mathbf{a} \mathrm{AlB}_{2}$, b $\mathrm{AlB}_{12}, \mathbf{c ~ T i B} 2$

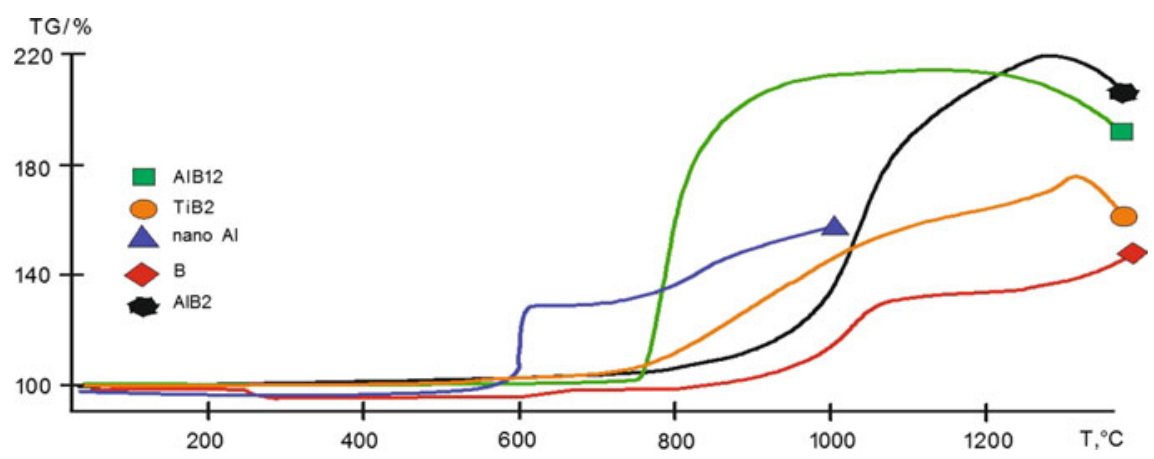

Fig. 4 Data TG analysis of boron, borides and nanoaluminum 


\section{Conclusion}

This paper has presented the techniques for the production of borides which can be used as fuels for high energetic materials hybrid solid-propellant rocket motor. The main characteristics of nano- and microparticles have been shown and discussed.

Synthesis of aluminum borides is one of the most promising areas in the field of development of new energy materials. Self-propagating high-temperature synthesis is the most suitable method for these purposes, which makes it possible to produce ultrapure products with target chemical and phase composition by adjusting the synthesis parameters. Previous studies have indicated that it is possible to produce borides with high content of target phase. According to DTA data, the degree of oxidation of obtained powders exceeds $95 \%$.

Acknowledgement Project was done with the financial support of the Russian Ministry of education and science, FOP "Research and development on priority directions of scientific-technological complex of Russia for 2014-2020". Agreement No 14.578.21.0034 5. June 2014. Unique project identifier: RFMEFI57814X0034.

\section{References}

1. Bondarchuk, S.S., Borisov, B.V., Zhukov, A.S.: Equations for calculation of parameters of reaching the steady-state mode of a solid propellant rocket engine for multi-component mixture of combustion products. Russ. Phys. J. 55(9/3), 24-26 (2012)

2. David, R., Lide (ed.): CRC Handbook of chemistry and physics. CRC Press, Boca Raton (2005)

3. Gany, A.: Combustion of boron-containing fuels in solid fuel ramjets. Int. J. Energ. Mater. Chem. Propul. 2, 91-112 (1993)

4. Gubertov, A.M., Mironov, V.V., Gollender, R.G. et al.: Processes in hybrid rocket engines. In: Koroteev, A.S. (ed.) FSUE Keldysh research center. Roscosmos, p. 405. Nauka, Moscow (2008)

5. Maslov, V.M., Borovinskaya, I.P., Ziatdinov, M.Kh.: Combustion of niobium-aluminium, niobium-germanium systems. Fiz. Goreniya Vzryva. 15(1), 49-57 (1979)

6. Merzhanov, A.G., Mukasyan, A.S.: Solid flame combustion, p. 336. Torus Press, Moscow (2007)

7. Varma, A.S., Rogachev, A.S., Mukasyan, S.H.: Combustion synthesis of advanced materials: Principles and applications. Adv. Chem. Eng. 24, 79-226 (1998)

8. Zhukov, A., Zhukov, I., Ziatdinov, M., Promakhov, V., Vorozhtsov, A., Vorozhtsov, S., Dubkova, Y.: Self-propagating high-temperature synthesis of energetic borides. In: Prospects of fundamental sciences development (PFSD-2016) proceedings of the xiii international conference of students and young scientists, vol. 1772(1), p. 020015. AIP Publishing, (2016, October) 
Open Access This chapter is licensed under the terms of the Creative Commons Attribution 4.0 International License (http://creativecommons.org/licenses/by/4.0/), which permits use, sharing, adaptation, distribution and reproduction in any medium or format, as long as you give appropriate credit to the original author(s) and the source, provide a link to the Creative Commons license and indicate if changes were made.

The images or other third party material in this chapter are included in the chapter's Creative Commons license, unless indicated otherwise in a credit line to the material. If material is not included in the chapter's Creative Commons license and your intended use is not permitted by statutory regulation or exceeds the permitted use, you will need to obtain permission directly from the copyright holder.

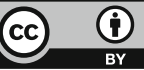

